\title{
Atendimento de gestantes na atenção primária a saúde pela enfermagem durante a pandemia do SARS-COV-2
}

RESUMO | Objetivo: Descrever o papel do enfermeiro na realização de consultas pré-natal durante a pandemia no âmbito da Atenção Primaria a Saúde. Método: Estudo descritivo, do tipo relato de experiência. O mesmo ocorreu no período de março de 2020 até junho 2020 na microrregião dos Sertões de Crateús, Ceará. Resultados: O profissional de enfermagem desenvolve o importante papel de orientar toda a população, em especial as gestantes, que são grupo de risco e ainda estão frequentando a unidade com certa periodicidade. Sob esse viés a educação em saúde em tempos de pandemia tem focado em medidas de prevenção contra o vírus SARS-Cov-2. Conclusão: Dessa maneira, a estratégia utilizada qualifica-se como um instrumento útil de fácil acesso e que gera impactos na população. Possibilitando uma intervenção continua no cuidado aos pacientes, no que tange ao atendimento pré-natal, a propagação de conhecimentos, age de modo a promover saúde e prevenir agravos.

Palavras-chaves: Infecções por Coronavirus; Educação em Saúde; Cuidado Pré-natal.

ABSTRACT | Objective: Describe the role of nurses in carrying out prenatal consultations during the pandemic within the scope of Primary the Health Care. Method: Descriptive study, an experience report. The same occurred in the period from March 2020 until June 2020 in the micro-region of the Sertões de Crateús, Ceara. Results: The nursing professional plays an important role in guiding the entire population, especially pregnant women, who are at risk and are still attending the unit with certain frequency. Under this bias, health education in times of pandemic has focused on preventive measures against the SARS-Cov- 2 virus. Conclusion: In this way, the strategy used qualifies as a useful instrument with easy access and that generates impacts on the population. Enabling a continuous intervention in patient care, with regard to prenatal care, the spread of knowledge, acts in a way to promote health and prevent injuries.

Keywords: Coronavirus Infections; Health Education; Prenatal Care.

RESUMEN | Objetivo: Describir la función del enfermero en la realización de consultas prenatales durante la pandemia en el contexto de la Atención Primaria de Salud. Método: Estudio descriptivo, relato de experiencia. Ocurrió en el período de marzo de 2020 a junio de 2020 en la microrregión de Sertões de Crateús, Ceará. Resultados: El profesional de enfermería desarrolla un papel importante en la orientación de toda la población, especialmente las mujeres embarazadas, que se encuentran en riesgo y aún asisten a la unidad con cierta frecuencia. Bajo este sesgo, la educación sanitaria en tiempos de pandemia se ha centrado en medidas preventivas contra el virus SARS-Cov-2. Conclusión: De esta manera, la estrategia utilizada califica como un instrumento útil, de fácil acceso y que genera impactos en la población. Permitir una intervención continua en la atención de las pacientes, en lo que respecta a la atención prenatal, la difusión del conocimiento, actúa con el fin de promover la salud y prevenir lesiones Palavras claves: Infecciones por Coronavirus; Educación en Salud; Atención Prenatal.

\section{Mirelly Shatilla Misquita}

Graduanda, Discente da Faculdade Princesa do Oeste.

ORCID: 0000-0001-7097-8651

\section{Patricia Gomes da Silva}

Graduanda, Discente da Faculdade Princesa do Oeste.

ORCID: 0000-0002-1843-4339

\section{Geovana de Abreu Braz}

Graduanda, Discente da Faculdade Princesa do Oeste.

ORCID: 0000-0002-2337-8044

\section{Anna Beatriz de Almeida Gomes Sousa}

Graduanda, Discente da Faculdade Princesa do Oeste.

ORCID: 0000-0001-8790-8895

\section{Dilene Fontele Catunda Melo}

Enfermeira. Mestra, Docente da Faculdade Princesa do Oeste.

ORCID: 0000-0001-9525-9389

\section{Francisca Nellie de Paula Melo}

Enfermeira. Doutora. Docente, da Faculdade Princesa do Oeste (FPO). ORCID: 0000-0002-9622-7669

Recebido em: 31/07/2020

Aprovado em: 24/08/2020

INTRODUÇÃO

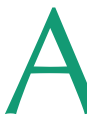
atenção primária a saúde (APS) de acordo com a Política Nacional de Atenção Básica é descrita por um conjunto de ações de saúde, no âmbito individual e coletivo. Que incorpora a promoção e a proteção da saúde, a prevenção de agravos, diagnóstico, tratamento, reabilitação, redução de danos e a manutenção da saúde. Possuindo o objetivo de desenvolver uma atenção integral que gere impactos na saúde e autonomia das pessoas adscritas pela unidade e nos determinantes e condicionantes de saúde coletiva ${ }^{(1)}$.

Assim, pode-se caracterizar a APS como a porta de entrada do Sistema Único de Saúde. Nesse contexto evidenciado acima e em meio a atual pandemia, essas unidades atuam de forma contínua e integrada nos cuidados ao paciente com COVID-19.

Diante do atual cenário global, com a pandemia da patologia causada pelo novo coronavirus, COVID-19, os profissionais de saúde encontram um dos maiores desafios da pratica profissional, a educação em saúde ${ }^{(2)}$.

A patologia resultante da infecção pelo novo coronavírus da sindrome respiratória aguda grave 2 (SARS-COV-2), designada COVID-19 pela Organização Mundial da Saúde (OMS) identificada pela primeira vez em humanos em dezembro de 2019, na cidade de Wuhan, na China. No dia 30 de 
janeiro de 2020, a OMS declarou estado de emergência em Saúde Pública em âmbito internacional, já no dia 11 de março foi declarado Pandemia.

Os sintomas e o desenvolvimento da infecção foram inicialmente comparados aos da gripe, porém poderiam evoluir para uma infecção aguda grave com pneumonia e exigir cuidados intensivos para 1 a $5 \%$ dos infectados ${ }^{(3)}$.

As principais vias de transmissão abrangem: gotículas de secreções de vias respiratórias de indivíduos sintomáticos e assintomáticos, e de objetos que venham a ser contaminados por eles ${ }^{(4)}$.

Diante da lacuna frente ao conhecimento acerca dos possíveis desdobramentos do SARS-CoV-2 no período gestacional, estudos analisaram inicialmente, que o número de gestantes infectadas era menor do que a população geral, entretanto, no caso de serem infectadas, apresentavam mais vulnerabilidade as manifestações mais agressivas da infecção. ${ }^{(5-6)}$

O Ministério da Saúde (MS) do Brasil incluiu em março de 2020 as gestantes como grupo de risco à COVID-19, com base nas alterações fisiológicas da gestação, as quais tendem a levar ao agravo em quadros de infecção, relacionado a baixa tolerância a hipóxia observada dentro dessa população ${ }^{(7)}$.

Diante desse aspecto, apesar de sensata a medida de precaução dos orgãos de saúde nacional, sabe-se que são poucas as pesquisas cientificas que permeiam a nova patologia em relação ao seu manejo a gestantes positivas para o SARS-Cov-2 ou casos suspeitos de infecção ${ }^{(8)}$.

Nesse contexto, os profissionais, não se preocupam apenas pelo avanço da patologia, mas pela dificuldade e resistência de adoção de medidas simples de cuidado em saúde, dentre estas podem ser citadas as que estão relacionadas a prevenção e ao combate da doença. Além disso os profissionais ainda têm que lidar com as chamadas Notícias Falsas que dificultando o processo de ensino-aprendizagem e são uma barreira para os profissionais de saúde ${ }^{(9)}$.

O enfermeiro como gerente de unidade, desenvolve um papel fundamental na orien- tação às famílias e a comunidade no que tange a promoção, proteção, prevenção de agravos e diagnósticos.

Desse modo, compreender o papel desses profissionais no enfrentamento a pandemia torna-se imprescindível. Portanto, o presente trabalho tem como objetivo descrever o trabalho do enfermeiro na realização de consultas pré-natal durante a pandemia no âmbito da Atenção Primaria a Saúde.

\section{METODO}

Trata-se de um estudo descritivo, do tipo relato de experiência. O presente estudo relata a dinâmica do enfermeiro de uma unidade de atenção primária a saúde (APS) do período de março de 2020 até junho 2020 na microrregião dos Sertões de Crateús, Ceará.

Foram utilizadas metodologias ativas de ensino, de modo que o conhecimento fosse repassado de modo transversal, onde pacientes poderiam expressar suas dúvidas e elencar situações vividas no cotidiano.

O local para a realização das atividades era na recepção da unidade, nesse local citado compreende um espaço amplo, arejado e com iluminação ambiente. Os presentes eram dispostos com uma distância mínima de um metro e meio entre um paciente e outro. A ação era realizada antes do atendimento de consulta pré-natal e levava em média de 30 minutos a 1 hora.

Para facilitar a compreensão foram utilizados cartazes, ilustrações e fala acessível e compreensível. Os assuntos eram abordados e escolhidos com antecedência e programado a melhor estratégia de trabalhar o assunto.

A pesquisa tem como população 52 gestantes que são atendidas na unidade por mês. Participavam por semana em torno de dez pacientes, grávidas que compareciam a aps para a consulta de pré-natal e demandas espontâneas as quais estivessem presentes eram convidadas a participar.

O momento era conduzido por duas enfermeiras com o apoio de 6 acadêmicas de enfermagem, que auxiliavam e falicitavam a discussão. A mediação ocor- ria de forma horizontal, onde a troca de saberes era estimulada.

Como medidas de prevenção todos os presentes na unidade usaram máscaras. Sendo que os profissionais utilizam máscara cirúrgica, já os pacientes poderiam utilizar mascaras de tecido ou qualquer outro modelo de máscara que ofereça proteção.

\section{RESULTADOS}

Na APS o enfermeiro é responsável pela realização da coleta de dados do paciente e detecção de casos suspeitos e confirmação através do teste rápido e avaliação dos critérios clínicos. O processo é realizado em sala reservada onde, após a realização dessa triagem, se o paciente se apresentar sintomático deve realizar o teste rápido após sete dias do surgimento dos sintomas.

Com a presença de sintomatologia ou teste rápido positivo, já ocorre a notificação, e o paciente é orientado a cumprir tratamento domiciliar sendo direcionado a unidade hospitalar caso necessite de atendimento especializado. Quando não é realizado a internação do paciente, a equipe de telemedicina do município faz o monitoramento daquele paciente por meio das mídias virtuais.

Além do papel do enfermeiro captação precoce do paciente suspeito e confirmado de COVID-19, o profissional ainda desenvolve o importante papel de orientar toda a população, em especial as gestantes. Que enquadram-se no grupo de risco e ainda estão frequentando a unidade com certa periodicidade.

A educação em saúde em tempos de pandemia tem focado em medidas de prevenção contra o vírus SARS-Cov-2, em que o enfermeiro, juntamente com outros integrantes da APS realizam orientações acerca de assuntos como: higienização correta das mãos, a utilização correta de álcool em gel, frequência da higienização, como lavar os alimentos corretamente, maneira correta de utilização de máscaras de tecido e como manuseá-la corretamente, sintomas que um paciente infectado pelo SARS-CoV-2 pode apresentar, além de tirar demais dúvidas que possam surgir durante o momento. 
A educação em saúde ocorre de maneira em que os participantes fiquem a uma distância segura, todos devidamente paramentados e seguindo as normas de etiqueta respiratória e os manuais de atendimento da Agência Nacional de Vigilância Sanitaria (ANVISA).

\section{DISCUSSÃO}

A realização do pré-natal apresenta um papel de fundamental relevância na prevenção e detecção precoce de patologias para mãe e bebe, a fim de proporcionar um desenvolvimento saudável para o feto e reduzindo riscos para a gestante.

Ressalta-se a importância dos profissionais de saúde assegurarem, á mulher sobre o direito da atenção humanizada durante a gravidez, parto e puerpério. Previstos pela Rede de Atenção a Saúde Materna e Infantil, conhecida como Rede Cegonha, instituido pela portaria $\mathrm{n}^{\circ}$ $1459 / 2011^{(10)}$

A atenção prioritária ás gestantes origina-se das caracteristicas relacionadas a gestação, onde ocorre alterações no metabolismo e no sistema imunológico adaptativas a gestação ${ }^{(4)}$.

A pandemia causada pelo SARS-CoV-2 apresenta-se de forma gravíssima, sendo altamente contagiosa e atingido a população mundial para além dos grupos de risco. Assim, ressalta-se a importância em conscientizar e sensibilizar a população sobre sua seriedade para reforçar medidas de preevenção com o intuito de reduzir e e controlar a patologia, $(4,11)$

A saúde é um direito universal, a promoção de saúde por meio de práticas educativas é uma ferramenta indispensável que deve ser utilizada, mesmo em épocas de pandemia, ela configura-se como uma alternativa indispensável para promover saúde apesar das dificuldades encontradas para se trabalhar em meio a atual, é de suma importância a captação precoce das gestantes.

Palácio\&Takenami citam em seus estudos que as práticas educativas precisam englobar o conhecimento de ambos os lados, saúde e educação para que as ações de cuidado sejam exitosas aqui inclui prevenção, proteção, promoção, reabilitação, cuidados paliativos e não apenas a cura de doenças ${ }^{(2)}$.

É notório que as ações de educação em saúde realizadas pelo enfermeiro são primordiais para conscientização da população quanto aos cuidados de higiene básica, bem como o uso obrigatório das máscaras, para que assim possa frear a disseminação do novo coronavírus.

Informações sobre as diferentes temáticas e vivênciaas, quando trocadas entre os profissionais de saúde e mulheres possibilita intercâmbio de experiências e conhecimentos, sendo caracterizada pelo Ministério da Saúde como a melhor forma de promover a compreensão do processo de gestação ${ }^{(12)}$.

Mascarenhas salienta em sua pesquisa a importância do cuidar continuado a gestante durante a pandemia. Logo os profissionais de saúde devem assegurar que seu atendimento humanizado será prosseguido de forma a assistir a gestante durante o prénatal, parto e puerpério. Assim, como a realização da puericultura do bebê que terá o acompanhamento do seu crescimento e desenvolvimento ${ }^{(8)}$.

As gestantes com COVID-19 possuem maiores chances de seu bebê entrar em sofrimento fetal e/ou parto pré-termo. Apesar de não haver estudos que comprovem a susceptibilidade o Ministério da Saúde preconiza as grávidas e puérperas como grupo de risco pois durante a fase gravídica e pós-parto a mulher encontra-se com o sistema imunológico alterado fisiologicamente propiciando o adoecimento pelo vírus. ${ }^{(13-14)}$.

Estudos apontam que a infecção por COVID-19 em gestantes tendem a desfechos negativos, tais quais: aborto espontâneo; rupture premature de membranas; restrição de crescimento intrauterine; sofrimento fetal, trabalho de parto e parto

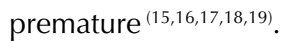

Nesse contexto, destaca-se o papel essencial do atendimento pré natal durante a gestação e a educação em saúde com foco em medidas de prevenção ao virus SARS-CoV-2, principalmente durante o terceiro trimestre de gestação, quando ocorrem os estágios finais de desenvolvimento fetal e maior nivel de ansiedade maternal ${ }^{(15)}$.

A OMS recomenda que seja realizado a educação da população em geral sobre a seriedade que cerca a COVID-19 e do papel do individuo na prevenção da propagação da patologia ${ }^{(20)}$.

Ao tratar-se de diagnóstico, pesquisas apontam a necessidade de promover a detecção precoce. Para isso, orienta-se que as gestantes saibam identificar sinais especificos da COVID-19, com o intuito de reduzir sua exposição aos serviços de saúde.(21)

Agência Nacional de Vigilância Sanitaria publicou em 30 de janeiro de 2020 a nota técnica $n^{\circ}$ 04/2020 que discorre acerca de orientações para serviços de saúde; divulgando medidas de prevenção e controle que devem ser adotadas durante a assistencia aos casos suspeitos ou confirmados de infecção pelo novo coronavirus ${ }^{(22)}$.

Salienta-se a importância de utilizar as medidas de prevenção e controle da COVID-19 durante a educação em saúde e promover a disseminação da mesma para os presentes a fim de quebrar a cadeia de transmissão do novocoronavírus.

O cuidado, dentro dessa pespectiva é indissociavel á noção de integralidade, caracterizando-se pelo ato de acolher, respeitar, tratar e atender o paciente. A utilização de técnologias leves diante da pandemia, contribui na produção de cuidado a partir da compreensão do usuário quanto á sua singularidade ${ }^{(23)}$.

\section{CONCLUSÃO}

A consulta pré-natal realizada pelo enfermeiro durante uma pandemia é fundamental, principalmente quando utiliza a educação em saúde que qualifica-se como um instrumento útil de fácil acesso e que gera impactos na população, sendo uma estratégia utilizada pelos profissionais de saúde para propagar conhecimentos de saúde.

Com metodologias leves, linguagem acessível e trabalhando temas de acordo com o ministério da saúde os profissionais conseguem impactar a comunidade de maneira positiva, propagando informações 
verídicas e sanando possíveis duvidas que possam surgir entre os espectadores.

Assim, conclui-se que essa ferramenta é de grande importância e de fácil aplicação que gera impactos satisfatórios e que pos- sibilita uma troca de conhecimentos entre pacientes e profissionais, estimulando o elo entre a comunidade e a equipe da APS.

Proporcionar assim, uma intervenção continua no cuidado aos pacientes, no que tange ao atendimento pré-natal, que envolve pacientes do grupo de risco para $\mathrm{CO}$ VID-19, a propagação de conhecimentos, age de modo a promover saúde e prevenir possíveis agravos. 1

\section{Referências}

1. Brasil. Portaria $\mathrm{N}^{\circ} 2.436$, de 21 de setembro de 2017. Aprova a Política Nacional de Atenção Básica, estabelecendo a revisão de diretrizes para a organização da Atenção Básica, no âmbito do Sistema Único de Saúde. Diário Oficial da União, seção 1, p. 68-76 Brasília, 22 de set. 2017. [Acesso em: 22 de jul. 2020]. Disponivel em: http://pesquisa.in.gov.br/imprensa/jsp/visualiza/index.jsp?data $=22 / 09 / 2017$ \&jornal $=1$ \&pagi na $=68 \&$ totalArquivos $=120$.

2. Palácio MA, Takenami I. Em tempos de pandemia pela COVID-19: o desafio para a educação em saúde. VD [Internet]. [Acesso em 22 de jul. 2020] Disponível em:https://visaemdebate.incqs.fiocruz.br/index.php/visaemdebate/article/ view/153

3. Russell TW, Hellewell JJCl, Zandvoort KVAS, Ratnayake R, Flasche S, Eggo RM, Edmunds WJ, Kucharski AJ. Estimating the infection and Case Fatality Ratio for COVID-19 Using Age-Adjusted Data from the Outbreak on the Diamond Princess Cruise Ship. medRxiv, 2020 [Acesso em: 22 de jul 2020]; Disponível em : https:// doi.org/10.2807/1560-7917.ES.2020.25.12.2000256

4. Royal College of Obstetricians and Gynaecologists (UK). The Royal College of Midwifes. Coronavirus (COVID-19) Infection in Pregnancy. Information for healthcare professionals. [Internet]. 2020 [Acesso em: 22 de jul. 2020]. Disponivel em: https://www.rcog.org.uk/globalassets/documents/guidelines/ 2020-04-03-coronavirus-covid19-infection-in-pregnancy.pdf

5. Rodriguez-Morales AJ, Cardona-Ospina JA, Gutiérrez-Ocampo E, Holguin-Rivera $\mathrm{Y}$, Escalera-Antezana JP, Alvarado-Arnez LE, et al. Clinical, Laboratory and Imaging Features of COVID-19: A systematic review and meta-analysis. Travel Med Infect Dis. 2020; [ Acesso em: 17 de ago. 2020] Disponivel em: https:/l pubmed.ncbi.nlm.nih.gov/32179124/

6. Chen H, Guo J, Wang C, Luo F, Yu X, Zhang W, et al. Clinical characteristics and intrauterine vertical transmission potential of COVID-19 infection in nine pregnant women: a retrospective review of medical records. Lancet. [ Acesso em 17 de ago 2020] Disponivel em : https://www.thelancet.com/pdfs/journals/lancet/ PIIS0140-6736(20)30360-3.pdf

7. Dong $Y, M o X, H u Y$, et al. Epidemiological characteristics of 2143 pediatric patients with 2019 coronavirus disease in China. Pediatrics. 2020. [Acesso em: 22 Jul. 2020]. Disponivel em: https://pediatrics.aappublications.org/content/pediatrics/early/2020/03/16/peds.2020-0702.full.pdf

8. Mascarenhas VHA, Caroci-Becker A, Venâncio KCMP, Baraldi NG, Durkin AC, Riesco MLG. COVID-19 e a produção de conhecimento sobre as recomendações na gravidez: revisão de escopo. Rev. Latino-Am. Enfermagem [Internet]. 2020 [ Acesso em 24 de jul 2020]; 28:e3348.Disponivel em: http://www.scielo.br/scielo.php?script=sci_arttext\&pid=S010411692020000100606\&lng=pt.

9. Neto M, Gomes T de O, Porto FR, Rafael R de MR, Fonseca MHS, Nascimento J. Fake news no cenário da pandemia de Covid-19. Cogitare enferm. [Internet]. 2020 [acesso em 24 de jul 2020]; 25. Disponivel em: http://dx.doi.org/10.5380/ ce.v25i0.72627.

10. Brasil. Ministério da Saúde. Secretaria de Atenção à Saúde. Departamento de Ações Programáticas Estratégicas. Portaria nº 1.459, de 24 de junho de 2011. Institui, no âmbito do Sistema Único de Saúde - SUS - a Rede Cegonha [Internet]. Brasilia: Ministério da Saúde; 2011 [Acesso 17 Ago 2020]. Disponível em: https:// bvsms.saude.gov.br/bvs/saudelegis/gm/2011/prt1459_24_06_2011_comp.html 11. Direção Geral de Saúde (PT). Norma n ${ }^{\circ} 007 / 2020$, de 29 de março de 2020 Prevenção e Controle de Infecção por SARS-CoV-2 (COVID-19): Equipamentos de Proteção Individual (EPI). [Internet]. 2020 [Acesso 17 Ago. 2020]. Disponivel em: https://www.dgs.pt/directrizes-da-dgs/normas-e-circulares-normativas/norma-n-0072020-de-29032020-pdf.aspx

12. Brasil. Ministério da Saúde (MS). Secretaria de atenção à saúde. Atenção ao prénatal de baixo risco.[internet] Brasília: MS; 2013. [Acesso em: 24 de jul. 2020]. Disponivel em: https://www.google.com/url?sa=t\&source=web\&rct=j\&url=http://bvs.saude.gov.br/bvs/publicacoes/atencao_pre_natal_baixo_risco. pdf\&ved=2ahUKEwjW8fPS2qPrAhVBLLKGHUhWA3oQFjAAegQIBXAC\&us$g=A O v V a w 1 b m 0 c \_$ljkAcUGomE2rpBeM

13. Rodrigues $C$, Barros H. Da emergência de um novo vírus humano à disseminação global de uma nova doença—Doença por Coronavírus 2019 (COVID-19). [Acesso em 24 de jul de 2020] Disponivel em: https://www.researchgate.net/ profile/Carina_Rodrigues13/publication/340006477_COVID19_Gravidez_e_ aleitamento materno/links/5e72989e4585152cdbfd566f/COVID-19-Gravidez-ealeitamento materno.pdf.

14. Müller EV, Campessato EA, Alves FBT, Favero GM, Ditterich RG. COVID-19 Orientações para gestantes e puérperas [livro eletrônico]. Paraná: 2020. [Acesso em 24 de jul de 2020]. Disponível em: https://corenpr.gov.br/portal/images/2020_comunicacao/EB-Covid19-Gestantes_e_Puerperas.pdf

15. Dashraath P, Jing Lin Jeslyn W, Mei Xian Karen L, Li Min L, Sarah L, Biswas A, et al. Coronavirus Disease 2019 (COVID-19) Pandemic and Pregnancy. Am J Obstet Gynecol [Acesso em 17 ago. 2020]. Disponivel em : https://pubmed.ncbi. nlm.nih.gov/32217113/

16. Liu Y, Chen H, Tang K, Guo Y. Clinical manifestations and outcome of SARS-CoV-2 infection during pregnancy. J. Infect. Dis. pii: S0163-4453(20)30109-2. [Acesso em 17 ago. 2020] Disponivel em: : https://ripetomato2uk.files.wordpress.com/2020/03/10.101640j.jinf_.2020.02.028.pdf

17. Chen S, Liao E, Shao Y. Clinical analysis of pregnant women with 2019 novel coronavirus pneumonia. J Med Virol. [Acesso em 17 ago. 2020] Disponivel em : https://onlinelibrary.wiley.com/doi/full/10.1002/jmv.25789

18. Qi H, Luo X, Zheng Y, Zhang H, Li J, Zou L, et al. Safe Delivery for COVID-19 Infected Pregnancies. BJOG. [Acesso em 17 ago. 2020]. Disponivel em : https:// pubmed.ncbi.nlm.nih.gov/32219995/

19. Liu D, Li L, Wu X, Zheng D, Wang J, Yang L, et al. Pregnancy and Perinatal Outcomes of Women With Coronavirus Disease (COVID-19) Pneumonia: A Preliminary Analysis. AJR Am J Roentgenol. [Acesso em 17 ago. 2020]. Disponivel em : https://pubmed.ncbi.nlm.nih.gov/32186894/

20. World Health Organization. Infection Prevention and Control during Halth Care When Novel Coronavirus (NCOV) Infection Is Suspected. OMS, 2020b. [Acesso em 17 Ago. 2020]. Disponivel em: <https://www.who.int/publications-detail/infection-prevention-and-control-during-health-care-when-novel-coronavirus-(ncov)-infection-is-suspected-20200125>.

21. Rasmussen SA, Smulian JC, Lednicky JA, Wen TS, Jamieson DJ. Coronavirus Disease 2019 (COVID-19) and Pregnancy: What obstetricians need to know. Am J Obstet Gynecol. 2020 May;222(5):415-26. [Acesso em: 18 ago. 2020] Disponivel em:https://www.scielo.br/scielo.php?script=sci_nlinks\&pi$\mathrm{d}=\mathrm{S} 01041169202000010060600017 \& \operatorname{lng}=e n$

22. Agência Nacional de Vigilância Sanitária (ANVISA). Nota técnica VIMS/ GGTES/ANVISA $n^{\circ}$ 04/2020. Orientações para serviços de saúde: medidas de prevenção e controle que devem ser adotadas durante a assistência aos casos suspeitos ou confirmados de infecção pelo novo coronavírus (SARS-CoV-2). Brasília, 2020. [Acesso em 18 ago 2020]. Disponivel em: http://portal.anvisa.gov. br/documents/33852/271858/Nota+T\%C3\%A9cnica+n+04-2020+GVIMS-GGTES-ANVISA/ab598660-3de4-4f14-8e6f-b9341c196b28

23. Ceccon RF, Schneider IJC. Tecnologias leves e educação em saúde no enfrentamento à pandemia da COVID-19: Tecnologias leves em tempos de pandemia [internet]. 2020. [Acesso em: 18 ago. 2020]. Disponível em: https://preprints. scielo.org/index.php/scielo/preprint/download/136/160/146 